\title{
Aprofundar o Método de François Delsarte: As atitudes do torso e o equilíbrio harmônico
}

\author{
Franck Waille \\ Laboratório de Pesquisa Histrica Rhône-Alpes (LARHRA), França \\ E-mail: franck.cw@gmail.com
}

Resumo

A reconstrução dos ensinamentos práticos (para o corpo, e mais ainda a voz) de François Delsarte levanta um verdadeiro desafio metodológico: se esses ensinamentos desempenharam um papel determinante no surgimento da modernidade das artes cênicas, práticas psicossomáticas e educação somática, eles foram essencialmente transmitidos "oralmente" de mestre para aluno. E eles foram, por um lado, perdidos. É a partir dos elementos de transmissão textual, associados a uma prática da dança moderna, do teatro e de abordagens somáticas, que é possível encontrar um entendimento o mais próximo possível de suas versões originais, sem ter a pretensão de poder voltar a esses. Ainda mais que as numerosas nuanças que Delsarte introduziu em seu ensino convidam a uma dinâmica aberta: não procurar "a letra" mas "o espírito" de seu trabalho, numa perspectiva de constante renovação. Essa abordagem é a da pesquisa de Franck Waille, que tem sido constantemente aperfeiçoada desde o início dos anos 2000. Ela diz respeito a diferentes elementos do expressivo método somático de Delsarte. Este artigo apresenta uma atualização sobre as atitudes do torso, favorecida pelo encontro com a pesquisa de Clóvis Massa sobre Delsarte feita no início dos anos 1990.

Palavras-chave

François Delsarte. Atitudes/Acorde de nona. Expressão de torso. Artes cênicas. Educação somática.
Abstract

The reconstruction of the practical teachings (for the body, and even more the voice) of François Delsarte raises a real methodological challenge: if these teachings played a determining role in the emergence of the modernity of the performing arts, practices psychosomatic and somatic education, they were essentially transmitted "orally" from master to student. And they were, for one, lost. It is from the elements of textual transmission, associated with a practice of modern dance, drama and somatic approaches, that it is possible to find an understanding as close as possible to their original versions, without pretend to be able to return to these. Especially since the many nuances that Delsarte introduced into his teaching invite an open dy-namic: not looking for "the letter" but "the spirit" of his work, in a perspective of constant renewal. This approach is that of the research of Franck Waille, which has been constantly refined since the beginning of the 2000s. It concerns different elements of Delsarte's expressive somatic method. This article presents an update on the attitudes of the torso, favored by the meeting with the research of Clóvis Massa on Delsarte made in the early 1990s.

Keywords

François Delsarte. Attitudes/Ninth Agreement. Expression of the torso. Scenic arts. Somatic education. 
Introdução

Em um artigo anterior ${ }^{1}$, eu apresentei minha abordagem renovada do trabalho das atitudes de pernas na obra de François Delsarte (1811-1871). Eu apresento agora minha abordagem renovada do trabalho das atitudes de pernas e da noção de "equilíbrio harmônico" característica das transmissões delsartianas. A abordagem renovada das atitudes de pernas foi beneficiada, durante o meu segundo pós-doutorado na Faculdade de Educação da Universidade Federal do Rio Grande do Sul (UFRGS) em 2016 et 2017, pelo encontro com a pesquisa de Clóvis Massa feita sobre Delsarte no início dos anos 1990. Essa pesquisa me levou a fazer uma releitura dos manuscritos com referência ao trabalho das pernas na obra de Delsarte, trabalho que se inscreve no contexto mais geral do treinamento expressivo das diferentes partes do corpo com o instrumental delsartiano denominado acorde de nona, que foi fonte de numerosas ambiguidades na transmissão e na recepção dos ensinamentos de Delsarte. Então, antes de apresentar por meio de textos e fotografias as contribuições combinadas de minhas pesquisas e as de Clóvis Massa em relação às atitudes das pernas, faço uma síntese com referência ao acorde de nona, a fim de meIhor apreender essas dinâmicas.

As atitudes das pernas são a base da organização corporal e da dinâmica. Mas as atitudes do torso representam elas também um grande papel na organização global do corpo, pelo fato de que o torso é o elemento central do organismo, e porque suas atitudes interagem automaticamente sobre as posições da cabeça e do pescoço, e desse modo sobre o "controle primário"2. Elas tem, desde então uma

1 Aprofundar o Método de François Delsarte: As atitudes das pernas.

2 Segundo F.M. Alexander, o "controle primário" [primary control] da coordenação do corpo estaria no nível do pescoço. A principal contribuição de Alexander é ter destacado a relação entre a cabeça, pescoço e costas: se essa relação é "justa", todo o corpo pode funcionar de forma otimizada. Em outras palavras, encontrar o alinhamento equilibrado e dinâmico destas três regiões, se restauraria o bom funcionamento do corpo e se ligação direta com a noção de "equilíbrio harmônico". Em minha tese Corpo, arte e espiritualidade em François Delsarte (1811-1871) (2009), eu me apoiei bastante no trabalho de equilíbrio harmônico a partir das informações fornecidas pela delsartiana americana Genevieve Stebbins (1977), as quais tem a imensa vantagem de ter uma grande clareza (lições muito organizadas e detalhadas). Mas eu havia levantado naquele momento diferenças em relação aos manuscritos mais próximos dos ensinamentos originais de Delsarte. Em meu livro 0 método somático expressivo de François Delsarte (2016), eu salientei essas diferenças e propus uma reorganização parcial do trabalho apresentado em 2009, sendo então mais fiel aos manuscritos delsartianos. Meu primeiro pós-doutorado feito no Departamento de Dança da Universidade do Quebec em Montreal (UQAM), em 2014 e 2015, me permitiu de antemão continuar a exploração de manuscritos em torno do trabalho do torso. Desde então, eu me deixei questionar novamente pelos diferentes manuscritos, e as contribuições do encontro com a pesquisa de Clóvis Massa em Delsarte, assinaladas em meu artigo anterior, também tiveram um impacto

\begin{abstract}
reabilitaria o reflexo de antigravidade natural, que pode ser geralmente observado em crianças pequenas (ver Alexander, 1996 [1923], capítulo 1 em particular). Há semelhanças com as pesquisas, ao mesmo tempo, de George Coghill sobre as salamandras (seu corpo é organizado a partir da cabeça - veja https:// www.alexander-technique.Iondon/alexander-technique-articles/ primária de controle /) e Rudolf Magnus em Zentralapparat (controle central "o chefe que leva" - ver http://alexander.area24.net/ RudolfMagnus-AnimalPosture.htm) (https: //www.alexander- technique.london/alexander-technique-articles/primary-control/). Alexandre provavelmente foi influenciado pelo trabalho de Delsarte, que ele conhecia e transmitia. Primeiro, porque em Delsarte a questão do equilíbrio e verticalidade é uma relação entre o tronco, cabeça e membros [ou da pélvis] (nós voltamos a isso nas páginas do artigo seguinte). Além disso, porque Delsarte mostrou o papel da cabeça nos movimentos expressivos: ele observou que "inflexões passam (...) alternadamente da mão à cabeça" (1839, p. 52) e, em seguida, falou sobre "transmissões" que ele também poderia descrever assim: "gestos que passam da cabeça a todos os agentes do corpo "(Mackaye, 1869/1870a, p. 72). Sua experiência de cantor certamente ajudou essas direções pedagógicas em relação à verticalidade assim como suas observações, visto que na canção "a emissão de um som harmonioso requer equilíbrio entre a cabeça e o resto do corpo, neste lugar estreito que é o pescoço' (Barthélémy, 1984, p. 39).
\end{abstract}


sobre a minha abordagem atual do trabalho do torso.

O presente artigo é então o terceiro elemento de um conjunto, cujos dois primeiros elementos (dinâmica do acorde de nona e a abordagem renovada das atitudes de pernas) foram apresentados em um artigo anterior. Quanto às pernas, apresento aqui minha apresentação sobre as atitudes do torso e a noção de equilíbrio harmônico com textos e imagens. Mais uma vez, as fotografias não pretendem ser versões definitivas, absolutas ou de referência dos exercícios a que se referem. São ilustrações simples de uma interpretação destes exercícios em um momento de minha pesquisa (elas provêm, além disso, de diferentes séries de pontos de vista). Elas tem então por único objetivo fornecer um suporte visual para o texto, e elas têm muitas imperfeições que o leitor vai me perdoar ... e que terá, espero, a oportunidade de apagá-las estando envolvido na prática dos exercícios expostos!

\section{As atitudes do torso e} a noção de equilíbrio harmônico

Como o tronco é o elemento central do corpo, ligando a pélvis e a cabeça no eixo vertical, desempenha um papel importante na organização geral do organismo e na sua dinâmica expressiva. Esta é a razão pela qual está necessariamente associada à noção de equilíbrio harmônico. Mas veremos que essa, reduzida em certas difusões americanas somente à gestão do torso, tem de fato uma aceitação mais ampla em Delsarte, e isso desde as origens de suas lições.

As atitudes do torso se beneficiaram apenas de um manuscrito delsartiano de 1839, o relatório de seus primeiros cursos de Estética Aplicada (é o mesmo manuscrito que me servirá de base para eu apresentar a visão mais ampla de equilíbrio harmônico). Pode-se facilmente imaginar que esse trabalho foi aprofundado durante os trinta e dois anos que o separam do fim da carreira de Delsarte em 1871. As difusões variadas dessas atitudes por todos os seus alunos que publicaram elementos de seu trabalho prático provavelmente levam em conta esses potenciais aprofundamentos. Mas veremos que o manuscrito de 1839 já possui um conteúdo de uma tal riqueza que nenhum dos estudantes diretos de Delsarte soube ou quis relatar na íntegra. Se eu tenho, desde a minha tese, enunciado essa riqueza, mostrando como a maioria das diferenças de transmissões poderia encontrar referências no que este manuscrito apresentou, faltava em minha demonstração a "prova pela imagem". Acontece que o aprofundamento do papel do tórax para as atitudes das pernas foi permitido pelo encontro com o trabalho de Clóvis Massa ocorreu no mesmo período de minha pesquisa em que voltei a esse manuscrito de 1839. Então há uma dinâmica em torno do torso na minha abordagem renovada dos ensinamentos delsartianos.

Nas fotografias que acompanham o restante deste artigo, apresento apenas as posições finais dos exercícios (eu apresentei versões anteriormente sequenciadas - ver Waille, 2011, p. 799-814, e Waille 2016, p. 381-426).

\section{As atitudes do torso no} manuscrito de 1839

O caderno de 1839, Escola de Delsarte, escola de canto moral e científico. Notas e relato de seus cursos 1839 , testemunha os dois primeiros meses de ensino público de Delsarte dentro do contexto do curso de Estética Aplicada, ministrados para um pequeno grupo de estudantes (ver Waille de 2011, p. 232-233). São esses alunos que reuniram no mesmo caderno as transcrições do ensinamento de seu mestre, com o apoio desse último, que relia e assinava esses documentos. $O$ trabalho era coletivo e se apoiava no conjunto das anotações espontâneas dos alunos tomadas in vivo, depois sintetizadas. Esta escrita tinha por objetivo deixar um rastro a ser consultado após as aulas, mas sobretudo alimentar a próxima aula, 
que começa com essa leitura. Ela é possivelmente enriquecida com "respostas a perguntas ou objeções" (Delsarte, 1839, p. 1). É somente após este trabalho em várias camadas que 0 resultado final é transcrito no caderno que chegou até nós. Este processo mostra uma clara consciência que tinha Delsarte e seus alunos da multiplicidade de formas de receber um ensinamento, e a necessidade de cruzar esses olhares diferentes para encontrar melhor o que queria dizer o mestre.

Aqui está a passagem deste caderno relativa às atitudes do torso. Eu apresento primeiramente a primeira parte desta passagem:

O tronco apresenta três aspectos e ainda revela o pensamento dos três estados já mencionados: se ele se apresenta na sua maior expansão, é colocado nesse caso para a frente, é a atitude de energético, é a atitude militar, vamos chamar de excêntrico. O torso ainda é apresentado de forma mais homogênea, menos contenciosa, mais afetiva, como é representada na bela estátua de Antinous, nós chamaremos de expansivo [normal]. Se os ombros se levantam e avançam, o peito se afundará e nos dará o aspecto comprimido [concêntrico] (Delsarte, 1839, p. 52).

Delsarte, portanto, começa com as três atitudes do torso no plano sagital (para frente e para trás), que é o plano mais imediato, porque o mais comum na experiência da vida cotidiana (é surpreendente que Stebbins (1977, Exercícios 1-3 do Capítulo II, p. 91-93³) começa a trabalhar no plano frontal: isto não é consistente com os ensinamentos de Delsarte, nem com a experiência motora humana, já que o plano sagital é o primeiro plano de desenvolvimento motor - ver Bainbridge-Cohen, 2002). Esses são, portanto, no contexto do acorde de nona, os três gêneros. Coloco entre parênteses o vocabulário característico da maioria dos cursos de Delsar-

3 Referimo-nos aqui não ao capítulo XII dedicado ao torso (é muito pobre), mas ao capítulo II "Harmonic Poise of Bearing" (1977, p. 91-102), que contém o essencial do trabalho prático para o tronco resultante do acorde de nona do torso de Delsarte (veja abaixo). te (concêntrico e normal, sendo anteriormente chamados comprimido e expansivo).

As fotografias destacam o fato que os três tipos de peito (Figura 1) envolvem cada uma oposição do tórax com a pelve e da cabeça (que aqui trabalham em simpatia: eles vão na mesma direção oposta à do tronco):

Figura 1: Os três gêneros (concêntrico, normal, excêntrico) do tronco (interpretação pela imagem).

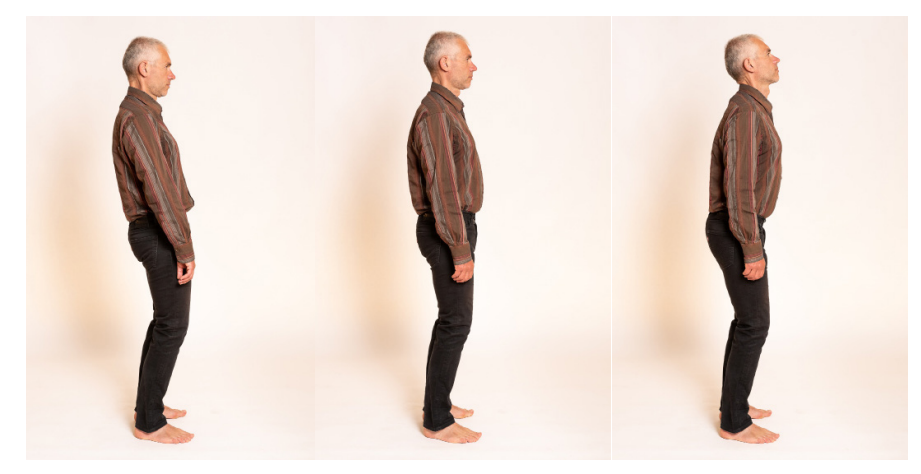

Franck Waille (fotografia @ David VENIER - Universidade Jean Moulin Lyon 3)

O trabalho dos três tipos do torso é a experiência mais simples a experimentar porque não envolve (ao contrário a esse dos lados, no plano frontal) transferência de peso (as oposições entre o tórax de um lado, a cabeça e a pélvis, de outro lado, permitem uma estabilidade da distribuição de peso ao nível dos pés). Além disso, é fácil associar a esse trabalho a adição do ritmo respiratório: na inspiração, o tórax está mais à vontade para a frente, e para trás na expiração. Concentrar-se no ritmo respiratório pode ajudar a entrar numa interioridade durante o trabalho e ter uma tomada de consciência precisa dos processos implementados em si nesta ocasião, a respiração convidando facilmente ("materialmente", pela jornada da respiração) a uma atenção dirigida para dentro e para o tórax.

Mackaye indica, para cada um dos gêneros (Figura 2), a soma de uma zona proeminente vindo diretamente da divisão estética do corpo em Delsarte (pelve, vital; zona epigástrica, anímica; parte superior do tórax, intelectiva): 
Figura 2: Tipo normal de tronco com destaque: pélvis/zona epigástrica/tórax superior (interpretação pela imagem)

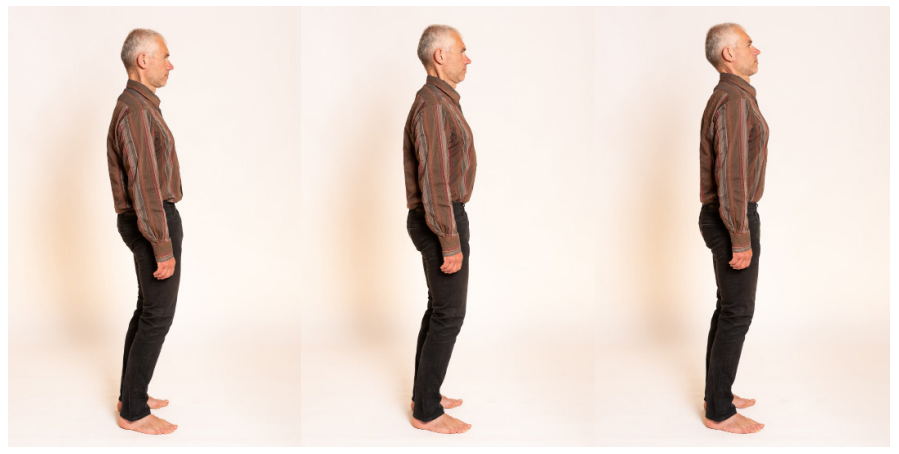

Franck Waille (fotografia @ David VENIER - Universidade Jean Moulin Lyon 3)

O trabalho no plano frontal (sobre os lados) é mais complexo devido à transferência de peso sobre uma perna ou sobre a outra indicada no final do texto de 1839, o que leva a ter não nove mas quinze tipos:

Estes três gêneros continuam a nos dar nove espécies: assim, em cada um desses gêneros, o torso será inclinado para o interlocutor, ou contrariamente a ele, nós teremos então três vezes três e, por consequência, o triplo acorde já indicado. Mas aqui ele apresenta formas adicionais que ainda não haviam sido apresentadas: assim, nós reconheceremos que o tronco inclinado em direção ao interlocutor pode colocar esta atitude alternadamente sobre 0 quadril direito ou esquerdo. Os seis movimentos pendidos se duplicam e nós teremos uma soma de quinze movimentos ou quinze espécies (Delsarte, 1839, p. 51-52).

A soma de quinze espécies indica que, para cada tipo, há quatro variações (não seis), o que quer dizer que a cada inclinação do tronco, há uma transferência de peso em uma ou outra perna (aqui não é considerada a distribuição igual de peso em ambas as pernas). $O$ gênero inicial é o quinto elemento para chegar a quinze espécies: cinco com o tipo normal + cinco com o tipo excêntrico + cinco com o tipo concêntrico. É isso, no gênero normal (Figuras 3 e 4), o que pode acontecer com um interlocutor à direita

(Figura 5):

Figura 3

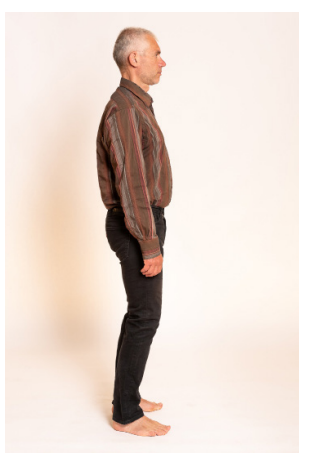

Figura 4

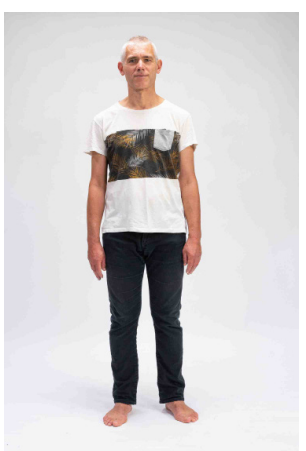

Franck Waille) (fotografia @ David VENIER - Universidade Jean Moulin Lyon 3)

Figura 5: Atitudes do torso no gênero normal: quatro espécies com o interlocutor à direita (interpretação pela imagem)

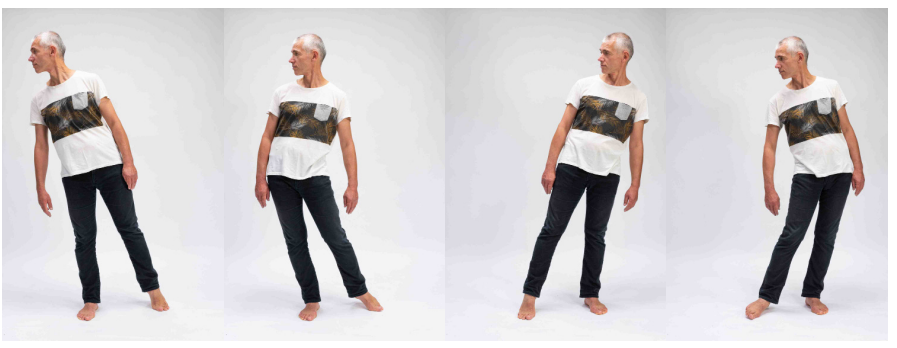

Franck Waille) (fotografia @ David VENIER - Universidade Jean Moulin Lyon 3)

Este acorde com quinze espécies se duplica de facto, na medida em que o interlocutor pode ser inclinado para a esquerda (Figura 6):

Figura 6: Atitudes do torso no tipo normal: quatro espécies com o interlocutor à esquerda (interpretação pela imagem)

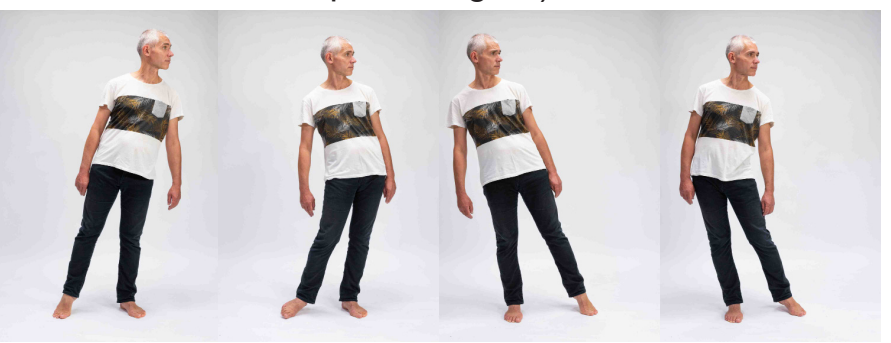

Franck Waille (fotografia @ David VENIER - Universidade Jean Moulin Lyon 3)

Estes exercícios também podem ser feitos 
sentados (Figura 7), já que isso é observado no cotidiano, o que corresponde ao tipo normal de pernas (pessoa sentada em um suporte) que apresenta Giraudet (1895, p. 87-93) e aos exercícios sentados transmitidos por Stebbins (1977, Exercícios 10 e 11 em particular):

Figura 7: Atitudes do tronco no gênero normal: quatro espécies enquanto está sentado (interpretação pela imagem)
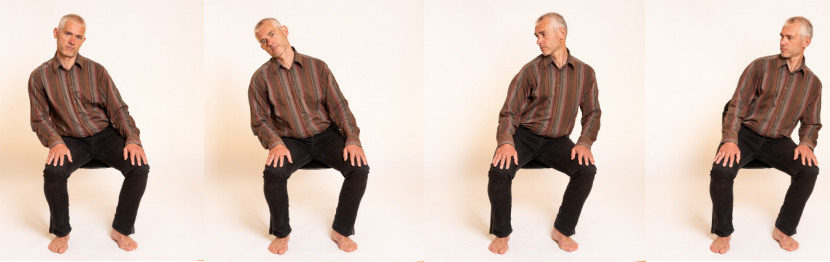

Franck Waille) (fotografia @ David VENIER - Universidade Jean Moulin Lyon 3)

A noção de inclinação do tronco exige observações:

1) É claro que o tronco pode se inclinar em todas as direções, não apenas nas laterais (no eixo frontal): o trabalho proposto é apenas uma base para considerar todas as possibilidades de movimentos do tronco em função de um interlocutor. Em transmissões de Giraudet e Stebbins, é claramente mostrado para trabalhar no eixo frontal (Stebbins adiciona em seguida as diagonais, fiel nisso à Médaille Inflective (Medalha das Formas dos Gestos) de Delsarte - ver Waille, 2016, p. 142-146);

2) O trabalho a partir da pesquisa de Clóvis Massa me leva a pensar a noção de inclinação do tronco (que conhecemos antes, especialmente quanto à quinta posição das pernas) de duas maneiras: ou mantendo os ombros rigorosamente no eixo frontal (como proponho na posição sentada), ou fazendo uma ligeira rotação na direção do interlocutor (como proponho na posição em pé).

Cada uma dessas possibilidades pode corresponder a uma situação expressiva diferente (se alguém estiver lado a lado com alguém, por exemplo, ou se estiver ligeiramente afastado da outra pessoa). No exercício, é a clara consciência do que é escolhido para experimentar que importa (então depois é possível escolher a outra possibilidade).

Além disso, se a outra pessoa (ou objeto) está à frente, a inclinação do tronco poderá ter um aspecto de reverência (Figura 8), ou simplesmente partir de um movimento para baixo (para escolher ou tocar um objeto, por exemplo) ou de uma posição baixa (se preparando para correr, por exemplo). Em todo caso, é o elemento central de uma oposição entre a cabeça e a pélvis (ou as pernas):

Figura 8: Torso inclinado para a frente no tipo normal: com marca de respeito/para agarrar um objeto/preparar-se para correr (interpretação pela imagem)

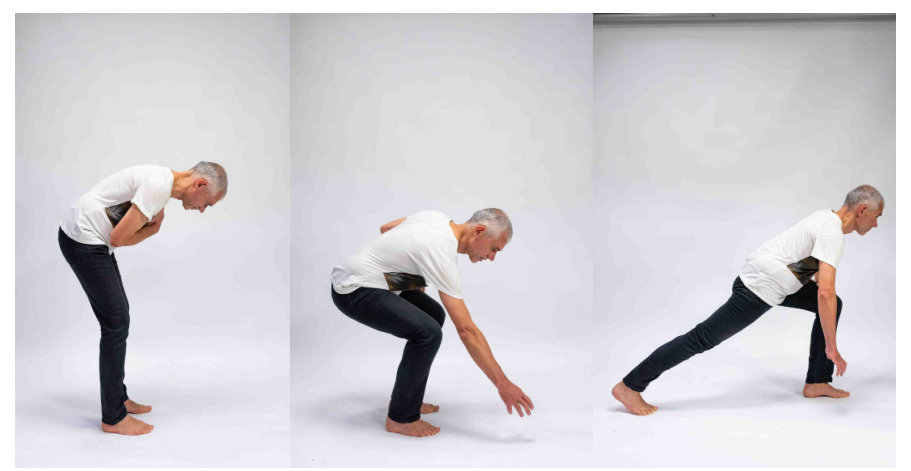

Franck Waille (fotografia @ David VENIER - Universidade Jean Moulin Lyon 3)

Se voltarmos ao texto de 1839 , vemos que as indicações dos três gêneros são diretamente expressivas, essas com relação às seis espécies igualmente (vínculo com um interlocutor), mas as com relação às formas adicionais (distribuição de peso em um ou outro quadril) não mais: são elas apenas posturais. É nesta medida que o trabalho das atitudes do tronco pode ser durante muito tempo somente relacionado ao trabalho de equilíbrio harmônico, como ocorre claramente em Stebbins.

\section{As atitudes do tronco e o equilíbrio harmônico nas transmissões americanas}

A noção de equilíbrio harmônico (e a de ginástica harmônica) foi debate na América do 
Norte quanto à sua origem (alguns têm questionado a paternidade de Delsarte sobre essas expressões e práticas a elas relacionadas). Eu mostrei como o essencial do manuscrito Harmonic Gymnastics de Mackaye poderia estar relacionado com os documentos indicando claramente a paternidade delsartiana (ver Waille, 2017). Acrescentamos que, se a documentação atualmente disponível (que é muito fragmentada, recordamos, especialmente ao nível da pedagogia do corpo e da voz - ver Waille, 2015a), as expressões de equilíbrio harmônico e de ginástica harmônica não se encontram, elas devem ser diretamente relacionadas com duas expressões próximas, as quais são identificáveis e tem a ver com o movimento expressivo, para o qual Delsarte utilizava um termo vindo de seu universo de músico e de cantor ("harmônica"): "o gesto é harmônico pela multiplicidade de partes que contribuem para sua formação "(1839, p. 23); e a "lei harmônica do gesto" (1858) para falar de sua grande lei do gesto, a das oposições (para o estática como para a dinâmica). $O$ adjetivo "harmônico" também é usado na sua pluma num contexto muito geral que resume a sua abordagem, como no título de uma das foIhas de sua escrita, que chegou até nós: Base da arte. Ciência das formas. Relação harmônica de corpo e alma (DC, caixa 1, pasta 21, item 1). Então, se nós não encontramos diretamente as expressões de equilíbrio e de ginástica harmônicos nos documentos que são acessíveis nos dias de hoje, isso não exclui que estas expressões não sejam dele, e que ele as tinha utilizado particularmente durante seus ensinamentos práticos.

Vamos lembrar aqui que a noção de gesto ou de postura harmônica deve ser ligada com diferentes partes do corpo que contribuem para o equilíbrio ou o movimento, e que esta é uma fonte de harmonia. Delsarte constatou o equilíbrio harmônico por suas observações do cotidiano como na escultura grega, a qual ele constantemente fazia referência quando se tratava das leis de harmonia e equilíbrio. ${ }^{4}$

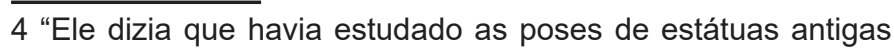

Mackaye transmitiu a noção de equilíbrio harmônico da seguinte forma:

O centro comum de todas as formas de movimento no corpo é o centro de gravidade que normalmente deve estar na vertical dos pés.

O equilíbrio desse centro, que deve ficar à perfeição com a forma física de sua ação expressiva, é chamado equilíbrio harmônico ou este equilíbrio do corpo sobre seus pés, o qual traz o conjunto de suas partes para ter entre elas, as melhores relações possíveis para que haja uma precisão sutil na sua cooperação harmônica. ${ }^{5}$

Em seguida, ele transmite (1886, Lição 4) duas séries de exercícios "para o estabelecimento de um equilíbrio harmônico instintivo" [ "for the establishment of an instinctively harmonic poise of the body"]. Proponho ilustrar desse modo (Figura 9) a primeira série (dois exercícios) que ele denomina de "equilíbrio harmônico para a unidade" (Harmonic poise for Unity 1886, p. 6-8):

Figura 9: Exercícios para o equilíbrio harmônico que promovem a unidade ["for Unity"] (Mackay, 1886, p. 6-8]

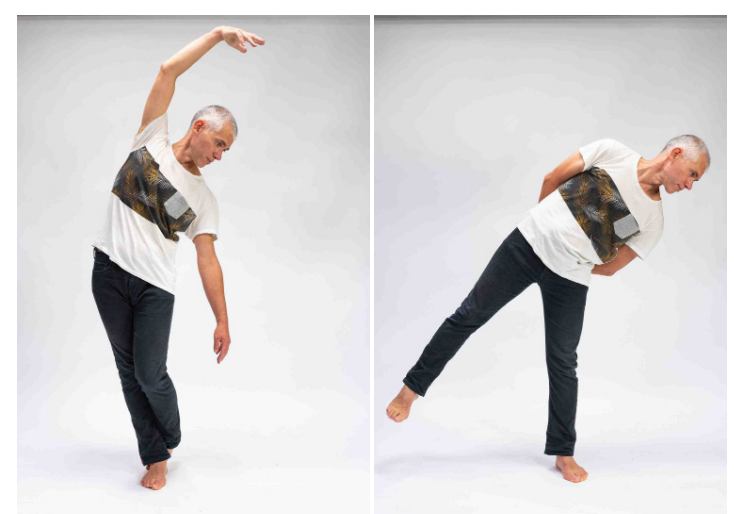

Franck Waille (fotografia @ David VENIER - Universidade Jean Moulin Lyon 3)

por quinze anos" (Arnaud, 1882, p. 198).

5 « The common centre of all forms of motion in the body, is its center of gravity, when normally erect upon its feet. The poise of this centre which most perfectly fits the physical forms for their expressive action, is called the Harmonic Poise. Or that poise of the body upon its feet which brings all its different parts into the best relation for a subtle precision of harmonic cooperation » (Mackaye, 1886, leçon 3, p. 5-6). 
Vamos ver abaixo como colocar esses exercícios em conexão com notas manuscritas de Delsarte.

Mackaye transmite em seguida uma série de "Exercícios de equilíbrio harmônico para a sensação de ser um" (Exercises in the harmonic poise for Oneness - 1886, p. 8-9). Proponho ilustrar o primeiro exercício da seguinte forma (Figura 10):

Figura 10: Exercício $n^{0} 1$ para o equilíbrio harmônico promovendo a sensação de ser um ["for Oneness"] (Mackaye, 1886, p. 8): para trás e para frente enquanto permanece em pé (interpretação pela imagem)

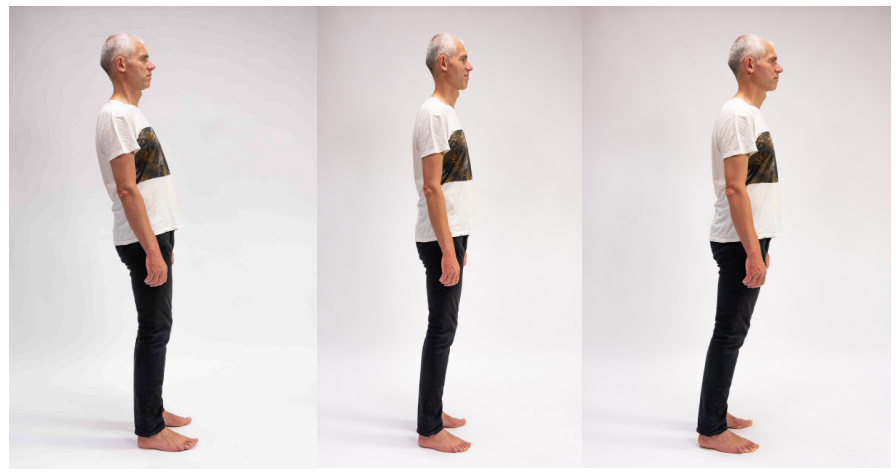

Franck Waille (fotografia @ David VENIER - Universidade Jean Moulin Lyon 3)

É a partir desse último exercício que podemos ilustrar a diferente concepção do equilíbrio harmônico que desenvolveu Stebbins, em relação a Mackaye. Mackaye privilegia a sensação de "ser um" associada à sensação do peso e à sua transferência no corpo; ele coloca assim a ênfase na associação que faz Delsarte entre o peso e a unidade, entre a sensação de peso e a sensação de si (ver Waille, 2016, p. 250257). Stebbins, por sua vez, privilegia as relações harmônicas das grandes partes do corpo durante essas transferências de peso. Em Stebbins, de fato, esses dois exercícios (Figura 11) se tornam:
Figura 11: Exercício para equilíbrio harmonioso no plano sagital $\left(n^{\circ} 7\right.$ e 8 na transmissão de Stebbins, 1977 , p. 96-97): oposições torso/cabeça \& pelve durante a transferência do tronco para trás e para a frente (interpretação pela imagem)
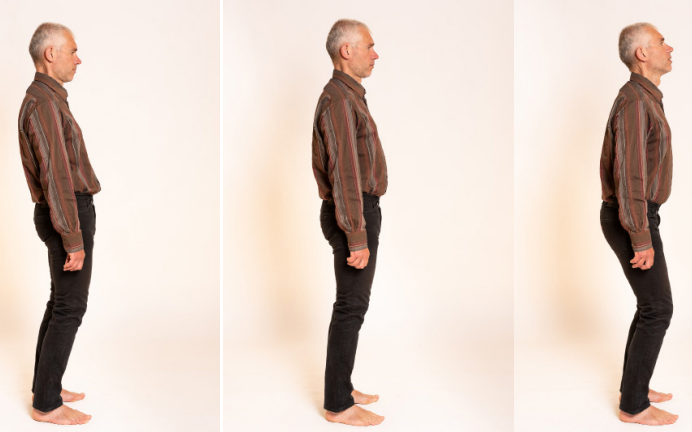

Franck Waille (fotografia @ David VENIER - Universidade Jean Moulin Lyon 3)

Vemos então que encontramos os três gêneros de atitudes do torso descritos por Delsarte em 1839. Neste caso, há bem menos utilização de músculos para mantê-las, uma vez que são as relações de oposição entre os elementos do eixo central do corpo que desempenham em grande parte este papel de manutenção. E a noção de equilíbrio é facilmente entendida: se na versão transmitida por Mackaye, o peso navega para a frente ou para trás do pé, na alternância dos três gêneros de torso utilizada aqui por Stebbins, a distribuição igualitária do peso em todo o pé permanece constante, o deslocamento do tórax em uma direção é compensado pelo da cabeça e pelve na outra (como indicamos para os três gêneros de tronco - veja acima) .

O segundo exercício "no equilíbrio harmônico para a sensação de ser um" (Exercises in the harmonic poise for Oneness - 1886, p. 8-9) transmitido por Mackaye é uma variação do primeiro, com as pernas afastadas. Ele é fortemente semelhante ao exercício proposto por Delsarte em torno da oitava atitude das pernas (a transferência gradual do peso sobre a perna que está avançada ou sobre a que está um recuada - ver abaixo), exceto que o início é indicado com o peso na perna estendida para trás (Figura 12): 
Figura 12: Exercício $\mathrm{n}^{\circ} 2$ de equilíbrio harmônico favorecendo a sensação de ser um ["for Oneness"] pernas separadas (Mackaye, 1886, p. 9) (interpretação pela imagem)

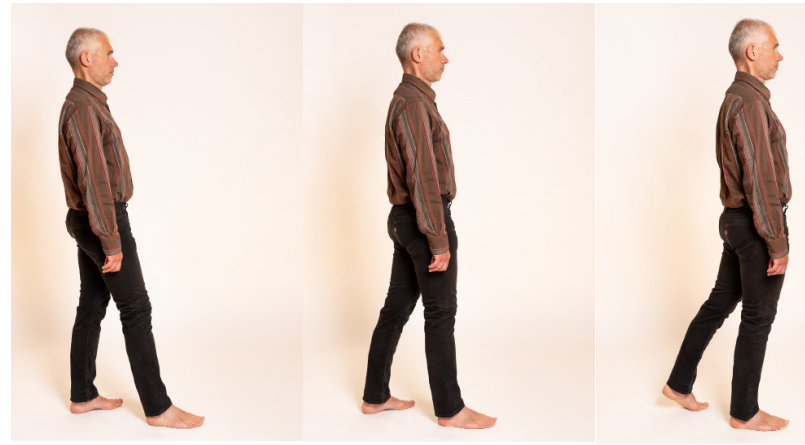

Franck Waille (fotografia (C) David VENIER - Universidade de Jean Moulin Lyon 3)

Stebbins também oferece uma versão com as pernas afastadas; em seguida, refere-se diretamente à antiga estatuária, o que é consistente com as indicações de Delsarte e a observação dessas estátuas apresentando oposições tórax/ cabeça \& pelve (Figura 13):

Figura 13: Exercício de equilíbrio harmônico no plano sagital pernas afastadas (Stebbins 1977, p. 94) (interpretação pela imagem) / Alexandre, o Grande (Museu do Louvre, sala do Manège, $n^{\circ}$. de entrada LL11)

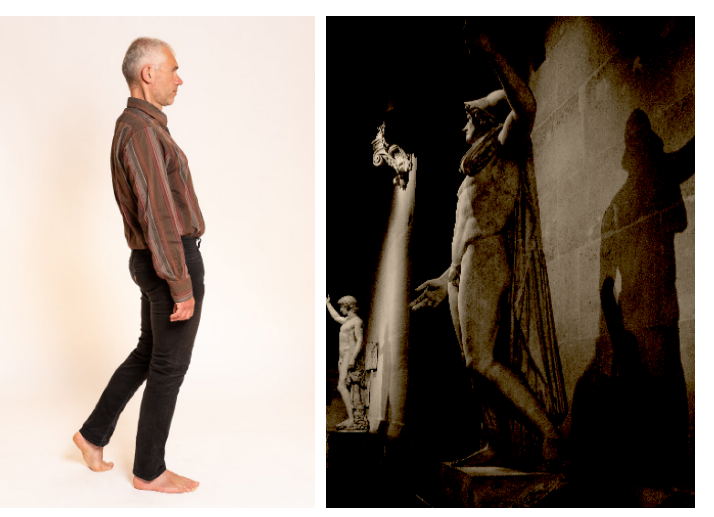

Franck Waille (fotografia (C David VENIER Universidade Jean Moulin Lyon 3) / fotografia@ autor

É provavelmente dessa observação da estatuária antiga que Delsarte retirou uma regra relativa à relação de simpatia entre a cabeça e a perna forte indicada por Delaumosne, o qual es- creve que "a cabeça deve estar voltada para o lado forte de perna" (1874, p. 77). Esta regra estrutura os exercícios transmitidos por Stebbins.

Stebbins, no segundo capítulo de seu trabalho sobre o Equilíbrio harmônico da manutenção [Harmonic Poise of Bearing] (1977, p. 91-102) utiliza uma grande parte da matéria do trabalho do tronco. No plano sagital, como acabamos de ver, mas também anteriormente no plano frontal, com as variações da distribuição de peso em uma perna e na outra, e fazendo alternar as posições com o interlocutor de um lado ou do outro. Ela seleciona assim uma parte dos dados das espécies de torso (Figura 14), que tem o achado pedagógico de fazer trabaIhar de maneira relacionada e repetitiva (ela indica passar de maneira fluída de uma posição a uma outra):

Figura 14: Exercícios de equilíbrio harmônico no plano frontal ( $n^{\circ} 1$ a 3 na transmissão de Stebbins, 1977, p. 91-93) (interpretação pela imagem)

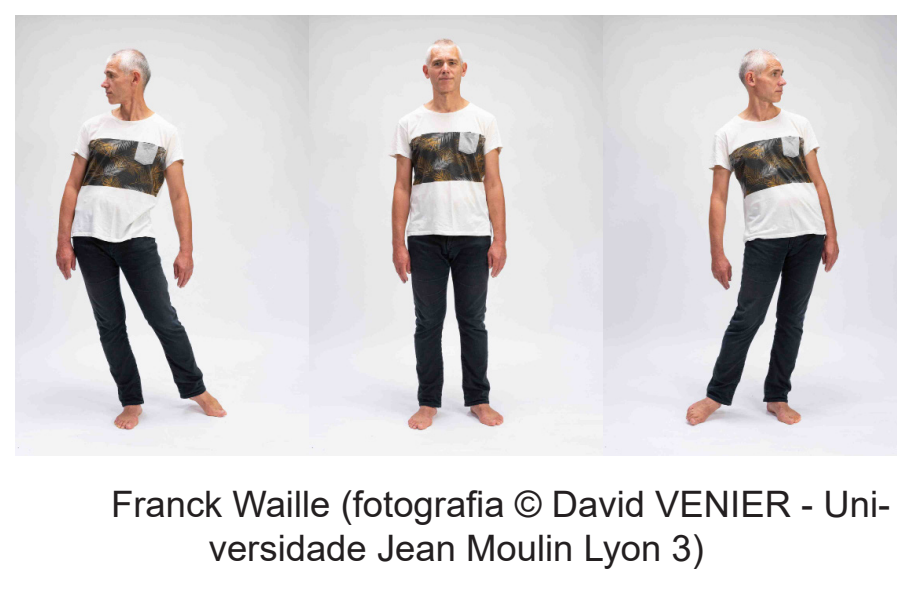

Eu já mencionei em minha tese que, em Stebbins, a décima-segunda lição sobre o torso apresenta uma grande anomalia em comparação com as lições que se relacionam às outras partes do corpo: se há apresentação das atitudes do torso, não há nenhum acorde de nona proposto, e sobretudo nenhum exercício correspondente. De maneira bastante incoerente, a seção "æsthetic gymnastics" concluindo esta pequena lição propõe de fato um trabalho para os braços (1977, p. 210-211) (enquanto que os braços já se beneficiaram com três lições anteriores). Todo o conteúdo da transferência de peso em uma perna e na outra é, portanto, pas- 
sado para os exercícios do segundo capítulo sobre o equilíbrio harmônico.

Em relação ao balanço das partes centrais do corpo chamado equilíbrio harmônico no delsartismo americano (veremos adiante que esta noção de equilíbrio harmônico era mais ampla na origem), Delsarte o constatou em torno dele. É o balanço natural que pode ser observado em pé, mas também e sobretudo na caminhada, como recordou a delsartista Henrietta Hovey (que trabalhou com Gustave Delsarte, filho de Francis, que continuou a transmissão dos ensinamentos de seu pai em Paris, após sua morte). Hovey indica que "a expressão do equilíbrio do corpo, desde o momento em que os pés estiverem envolvidos, só deve ser estudada através da caminhada". 6 Podemos descobrir, estando atentos aos nossos movimentos quando caminhamos, as relações torso/cabeça \& pelve em todos os planos e rotações (a caminhada humana sendo contralateral). Hovey indica que o que é denominado de equilíbrio harmônico na América do Norte (o "chamado equilíbrio harmônico") é uma posição pela qual passamos quando damos um bom passo. ${ }^{7}$ A caminhada apresenta relações harmônicas entre a cabeça, o tronco e a pelve em todos os planos de maneira simultânea. Os exercícios que são tirados dele individualizam cada plano de forma específica e sucessiva, entendendo-se que são apenas um tempo de aprendizado.

Delsarte também constatou este balanço sobre as estátuas antigas, balanço aparecendo a partir do Le Doryphore (o portador de lança) do escultor grego Polyclèto (século $V$ a. C.), que serviu de modelo estético - às vezes é denominado Canon (ver Muller-Dufeu, 2002, p. 397). Le Doryphore "é a primeira espécie de corpo masculino de beleza idealizada na arte grega clássica. (...) Sua forma equilibrada e sua posição em contraposto (uma perna dobrada determina a inclinação dos quadris, dando um movimento

6 «The expression of a poise of the body should so far as the feet are concerned, be studied through walking only » (TSC, fol$\operatorname{der} 728$, p. 1).

7 " The so called harmonic poise (...) is a pose to which we come or through which we pass in taking a good step » (id. : 5). virtual à figura) fazem nascer a noção ocidental de equilíbrio perfeito na relação entre as partes do corpo e o conjunto". (Smalls, 2003, p. 266, nota 19). É uma "representação dinâmica do corpo através do movimento se enrolando em torno de um eixo central (...) uma combinação de movimento e de repouso, de equilíbrio e de assimetria: uma dança dos opostos" (Barba, Savarese, 2008p. 170). O meu entendimento de estatuária grega clássica é que esta escultura tem uma parada em um ponto de andar, como uma fotografia gravada na pedra: é por essa razão que ela contém todos os elementos do que até aqui chamamos equilíbrio harmônico.

\section{A noção completa de equilíbrio harmônico}

Se é evidente que as posições do tronco, e, portanto, sua relação com pernas e cabeça, desempenham um papel central no equilíbrio harmônico, é importante notar que, em Delsarte, este equilíbrio harmônico incorpora o que eu acabo de apresentar, mas vai além disso. Assim, no relatório dos cursos de 1839 , encontramos indicado:

(...) vamos à aplicação, e começamos com as leis do equilíbrio. Eles são muito simples, embora difíceis de observar.

$1^{\circ}$ À inclinação do tronco corresponde o alongamento da perna na direção oposta.

$2^{\circ}$ Quando um braço é adicionado ao peso do tronco já inclinado, o outro braço deve se erguer para formar um contrapeso.

$3^{\circ} \mathrm{Na}$ inclinação da cabeça, responde ainda a inclinação oposta do tronco.

$4^{\circ}$ Olhando para o fundo de um poço, os dois braços podem recuar para trás se também for suportado pelas duas pernas; como também os dois braços podem ir para a frente como resultado de um recuo do torso para trás. Mas esta somente é tolerável na primeira ou num atitude semelhante, tal como a segunda aproximada ou uma pequena terceira (Delsarte, 1839, p. 24). 
Neste texto, "primeira", "segunda" e "terceira" designam as três primeiras atitudes das pernas. Cada um destes quatro pontos daria origem a um ou a específicos exercícios, os quais deveriam poder se encontrar nos exercícios transmitidos pelos estudantes de Delsarte.

O primeiro ponto, por exemplo, inspira directamente o exercício transmitido por Mackaye "para a unidade" [Harmonic poise for Unity] em que o tronco está em oposição à perna elevada (no plano frontal então). Eu, além disso, as apliquei nas fotografias que apresentam os exercícios do acorde de nona do tronco. A oposição entre o tronco e a perna é a base das oposições entre o tronco e o quadril, quando o peso recai sobre essa perna e, portanto, ela não pode se afastar (nós vimos exemplos desse tipo nas atitudes do torso).

O segundo ponto nos faz pensar no arabesco na dança acadêmica, arabesco ao qual cheguei por uma simples extensão de um exercício de Delsarte transmitido por um de seus desenhos e que apresenta a sucessão de uma série de oposições entre diferentes partes do corpo (cabeça/mão; tórax/ cabeça e pelve; pelve/cabeça; tórax/perna; braço/perna) (ver Waille, 2011, p. 825-826, e Waille, 2016, p. 422-426); ele indiretamente inspirou a outro dos outros transmitidos por Mackaye "para a unidade" (a adição do braço para o peso do tronco não é então compensada pela elevação do outro braço, mas é o deslizar da pelve em oposição que faz o contra-peso).

O terceiro ponto, por sua vez, é o que sustenta as relações de oposição entre a cabeça e o tórax no trabalho das atitudes do tronco (e isso também se encontra igualmente no trabaIho das atitudes de cabeça, a qual, sem isso, se tornaria um trabalho puramente mecânico e insípido).

O quarto ponto é encontrado em vários exercícios publicados por Giraudet, que além disso transmite um grande número de exercícios de oposição para diferentes partes do corpo (cabeça/ ombro; cabeça/tronco; braço/cabeça; braço/torso, etc.) (1895, p. 103-105 + desenhos XXIX-XXI).

É significativo que Delsarte começa bem, nessa época, seus cursos práticos pela questão do equilíbrio do corpo, e esse equilíbrio é concebido como a cooperação harmoniosa de diferentes agentes: isso é estritamente a noção de equilíbrio harmônico (mesmo se ela não for assim chamada neste manuscrito).

É notável que todas as indicações dadas aqui se referem à oposição entre o tronco e outras partes do corpo (perna, braço, cabeça). Isto indica claramente que para Delsarte, desde o início de seu ensino, o tronco tem um papel central no trabalho da oposição, e, assim, no equilíbrio geral do corpo, ou seja, em outras palavras, nas questões posturais. $\mathrm{E}$ o trabalho das atitudes do torso, neste mesmo manuscrito, segue imediatamente essa passagem inicial sobre 0 equilíbrio.

Mas em outro manuscrito, vemos que Delsarte, durante uma conferência, indica que o equilíbrio também é trabalhado com as outras partes do corpo:

Quando meu braço sobe em direção à minha cabeça, minha cabeça faz a metade do caminho e se inclina. Aqui está uma oposição de movimentos. Se minha mão se soltar, minha cabeça se eleva e esse pequeno movimento de retorno produzido pela punho ecoa na cabeça. Não há movimento na mão que não tenha seu eco, sua repercussão na cabeça. (...) Se eu virasse minha cabeça com um movimento semelhante do braço, cairia (1858).

Assim, vemos que a lei dos opostos, a pedra angular da estática como da dinâmica em Delsarte (ver Waille, 2016, p. 205-213), é a lei que rege o equilíbrio harmônico em todas as situações expressivas. Diz respeito tanto às relações dos elementos do eixo central do corpo (torso, cabeça, pélvis-pernas) como as relações entre os outros elementos corporais. É através dela que, para Delsarte, se estabelece a harmonia no movimento, indissociável de uma certa qualidade ou estado de corpo, que ele evoca pela expressão de "facilidade na força" (Mackaye, 1869 / 1870b, p. 91), ou "força e doçura" (Delsarte, s/d), ou ainda "energia suave" (ibid.). 


\section{Conclusão}

As novas abordagens que apresento aqui de algumas informações vindas de manuscritos ou publicações fazem eco, de um ponto de vista metodológico, à advertência que foi feita nas minhas publicações de 2011 e de 2016: no momento em que são feitas, as fotografias são minha compreensão das informações coletadas e uma parte do meu comentário sobre essas informações. Eles não têm nem caráter normativo nem pretensão estéticas: não se trata de fornecer a boa maneira de fazer estes exercícios, mas de apresentar uma ferramenta de comunicação tornando mais acessível descrições muitas vezes difíceis de acessar pelo viés de um texto. Se elas tentam ser o mais fiel possível às fontes em que se baseiam, elas não são menos a minha interpretação em algum momento dado das informações coletadas, ainda mais porque inevitavelmente levam em conta as realidades do corpo fotografado em seus aspectos anatômicos como em sua experiência anterior de movimento. Elas são, por natureza, sujeitas a evoluir, e é a primeira razão deste artigo: propor uma atualização de possíveis interpretações de documentos, atualização que também permanece sujeita a evoluir. Além disso, a variedade de informações transmitidas por diferentes alunos e/ou documentos certamente remete às diferentes variações e nuanças que Delsarte introduziu em seus ensinamentos, variações que convidam a essa dinâmica aberta e constante suscetível a nova interpretação. $O$ encontro com a abordagem de Clóvis Massa colocou em questão a riqueza dessa variedade de interpretações possíveis.

Os exercícios apresentados neste artigo, para o torso mas também para as pernas (no artigo anterior) e, em geral, tudo relacionado à oposição das diferentes partes do corpo em vista do equilíbrio e da harmonia em estática como na dinâmica, são elementos centrais no trabaIho expressivo delsartiano, uma vez que participam diretamente da construção de um equilíbrio harmonioso e harmônico que serve de base para a expressão. Para retomar as palavras de Mackaye, este trabalho "tende a desenvolver no indivíduo uma obediência instintiva, inconsciente, sem esforço e espontânea às leis universais que desenvolvem a fluência, a precisão e a harmonia do movimento, e com isso sublima e dá o poder à expressão humana". ${ }^{8}$ Trata-se, em última análise, de um processo de reorganização motora baseado em observações minuciosas dos funcionamentos mais eficazes e naturais. Compreendemos "naturais" no sentido aristotélico do termo: "(...) a natureza não faz nada em vão, mas realiza sempre o melhor entre as possibilidades que correspondem à essência de cada animal." (Aristóteles, 1973, p. 13 [Caminhada dos animais, 2, 704 b]). Isto se reflete em termos de funcionamento eficaz em uma teoria recente de controle do movimento apresentada por Alain Berthoz, que sugere "que o sistema motor executa os movimentos de acordo com o princípio de mínima energia." (1997, p. 165). Torna-se claro que, em Delsarte estamos em um processo de trabalho em profundidade sobre o funcionamento da pessoa, a qual inicialmente pensada em um ótica expressiva, inclui uma dimensão de reorganização motora do tipo terapêutico. Se essa pode ser dissociada da ótica artística inicial de Delsarte, poderia ser interessante, no entanto, estar na escuta de uma outra proposta desse último. O artista do século XIX sugeria que a dimensão expressiva do ser humano é o que permite por excelência a unidade da pessoa, a ligação profunda entre o corpo e o que o anima, a alma (cf. Waille, 2011, p. 311-312). Tratar-se-ia então de voltar o ponto de vista e questionar o que é a terapêutica e a viabilidade para essa de se dissociar da perspectiva expressiva associada a essa da unidade da pessoa. E se, finalmente, o expressivo não estivesse a serviço do terapêutico, mas o terapêutico fosse uma dimensão do expressivo? Ou ainda, e se o terapêutico e o expressivo fossem inseparáveis? Talvez a dimensão expressiva poderia ser o horizonte mais desejável para a

\footnotetext{
8 «(...) a series of exercices have been invented called Harmonic gymnastics which seek[s] to develope an instinctive, unconscious, effortless, and spontaneous obedience, on the part of the individual, to those universal laws which develope ease, precision and harmony of motion, and thus sublimate, and potentize expression of man » (Mackaye, 1886, p. 5).
} 
pessoa, aquele em direção do qual ela seria mais plenamente ela mesma, ou faria agir em sinergia todas as suas dimensões, incluindo a sua dimensão espiritual? Parece-me que é isso que nos sugere, nesse início do século $X X I$, o artista e o pedagogo do século XIX.

\section{Abreviaturas}

DC [= Coleção Delsarte]: "Documentos de François Alexandre Nicolas Delsarte, Mss. 1301, Louisiana e Lower Mississippi Valley Coleções, bibliotecas LSU, Baton Rouge, The. "

FH: Hamel fonds, Fundos dos arquivos do Séminaire de Québec: SME (1626-1994), Museu da civilização, Coleções, Arquivos Históricos e Serviço de Bibliotecas, Quebec, Quebec, Canadá.

MPF: Os papéis da Família Mackaye, Biblioteca Baker, Coleções Especiais, Dartmouth College, Hanover, New Hampshire, EUA (Manuscrito ML-5, Série 7, Steele MacKaye, 18481916, caixa de 7 \& 8 / Manuscrito ML-5, Series 22, Addendum 1, box 219).

$\mathrm{PRH}$ : Os Documentos de Richard Hovey, Biblioteca Baker, Coleções Especiais, Dartmouth College, Hanover, New Hampshire, EUA.

TSC: Coleção Ted Shawn, Lincoln Center, Divisão de Dança Jerome Robbins, Biblioteca Pública de Nova York para as Artes Cênicas, Nova York, EUA, Classificação: (S) * MGZMC-Res. 31, série VIII "Sistema Delsarte de Expressão".

Bibliografia e fontes (impressas ou manuscritas)

ALEXANDER, Frederick Mathias. L'usage de soi. Bruxelles: Éditions Contredanse [The Use of the Self], 1996 [1923].

ARISTOTE. Marche des animaux. Mouvements des animaux. Index des traités biologiques. Paris: Les Belles Lettres, 1973.
ARNAUD, Angélique. François del Sarte, ses découvertes en esthétique, sa science, sa méthode, précédé de détails sur sa vie, sa famille, ses relations, son caractère. Paris: Ch. Delagrave, 1882.

BAINBRIDGE-COHEN, Bonnie. Sentir, ressentir et agir. L'anatomie expérimentale du Body-Mind Centering ${ }^{\circledR}$ (traduction de Sensing, feeling and action, par Madie Boucon). Bruxelles: Nouvelles de Danse no 50, 2002.

BARBA, Eugenio. SAVARESE, Nicola. L'Énergie qui danse. Dictionnaire d'anthropologie théâtrale, Montpellier: L'Entretemps, 2008.

BARTHÉLÉMY, Yva. La voix libérée. Paris: Robert Laffont, 1984.

BERTHOZ, Alain. Le sens du mouvement. Paris: Odile Jacob, 1997.

BERTHOZ, Alain. La décision. Paris: Odile Jacob, 2003.

CABLE (s.d.), Notebook of Cable while studying with Delsarte [cahier de Cable étudiant avec Delsarte] (DC, box 2c, folder 132).

CHEVALIER, Jean; GHEERBRANT, Alain. Dictionnaire des symboles. Paris: Bouquins, Robert Laffont / Jupiter, 1982.

DAWN CLARK, Janis. The Influence of the Delsarte System of Expression on American Acting 1871-1970. Ph.D. Dissertation, Washington State University, 1982.

DELAUMOSNE, Abbé. Pratique de l'art oratoire de Delsarte. Paris: Joseph Albanel, 1874.

DELSARTE, François. École de Delsarte, École de chant morale et scientifique. Notes et compte-rendu de ses cours, 1839 (DC, box 11b, folder sans \#). Différents transcripteurs, avec annotations et signature de Delsarte, 1839. 
DELSARTE, François. Cours de M. Delsarte aux Sociétés savantes, cours no 8 (DC, box 12 b, folder 54). 1858.

DELSARTE, François. Esthétique appliquée, cours de F. Delsarte. Exposition en neuf leçons de l'art de l'orateur, du peintre et du musicien. Offert à $M$. Delsarte par son élève Alphonse Pages (DC, box 12c, folder 40), 1859.

DELSARTE, François. Beau (DC, box 9-10, folder OS 36a, document 3). (s.d.).

FERNANDES, Ciane. The Moving Researcher: Laban/Bartenieff Movement Analysis in Performing Arts Education and Creative Arts Therapies. Kingsley: Jessica Publisher, 2014.

GIRAUDET, Alfred. Mimique, Physionomie et Gestes. Méthode Pratique D'après le système de François Del Sarte pour servir à l'expression des sentiments. Paris: Ancienne Maison Quantin / Librairies-Imprimeries Réunies, 1895.

GODARD, Hubert. "Le geste et sa perception." In: GINOT, Isabelle; MICHEL, Marcelle. (Org.). La Danse au XXème Siècle. Paris: Bordas, 1995, p. 224-229.

GUIDO, Laurent. L'Âge du rythme - Cinéma, musicalité et culture du corps dans les théories françaises des années 1910-1930. Lausanne: Éditions Payot/Jacques Scherrer éditeur, 2007.

HAMEL, Thomas-Étienne. Cours d'éloquence parlée d'après Delsarte. Québec: Imprimerie de la compagnie de l'Événement, 1906.

JOUSSE, Marcel. Étude de psychologie linguistique. Le style orale rythmique et mnémotechnique chez les verbomoteurs. Paris, Beauchesne, 1925.

LABAN, Rudolf. La maîtrise du mouvement. Arles: Actes sud, 1997.
MACKAYE, James Steele. Notebook of Mackaye while studying with Delsarte \#3/7 [cahier de Mackaye étudiant avec Delsarte no 3/7] (DC, box 12b, folder 7), 1869/1870a.

MACKAYE, James Steele. Notebook of Mackaye while studying with Delsarte \#12 [cahier de Mackaye étudiant avec Delsarte no 12] (DC, range 35$), 1869 / 1870 b$.

MACKAYE, James Steele. Harmonic Gymnastics (DC, box 6, folder 76), 1886.

MASSA, Clóvis Dias. A significação corporal a partir de François Delsarte. Projeto de Graduação, ligado à FAPERGS através da pesquisa teórica "Emprego de Signos Gestuais", Departamento de Arte Dramática da Universidade Federal do Rio Grande do Sul (UFRGS). Porto Alegre, 1991.

PORTE, Alain. François Delsarte, une anthologie. Paris, IPMC. 1992.

PRADIER, Jean-Marie. La scène et la fabrique des corps. Éthnoscénologie du spectacle vivant en Occident. Ve siècle avant Jésus-Christ-XVIIle siècle. Talence: Presses Universitaires de Bordeaux, 2000.

RUYTER, Nancy Lee Chalfa. «Delsarte, son système et les États-Unis », in François Delsarte, 1811-1871. Sources-Pensée. ChâteauvalIon, Théâtre National de la Danse et de l'Image, p. 33-37, 1991.

SMALLS, James. L'homosexualité dans l'art. New York: Parkstone Press, 2003.

STEBBINS, Genevieve. Delsarte System of Expression. New York, Dance Horizons (réédition de la 6e édition [1902] de l'ouvrage de Stebbins, initialement intitulé Delsarte System of Dramatic Expression, publié pour la première fois en 1885), 1977. 
VAN HYMBECK, Auguste. Résumé des leçons de chant, grammaire, d'attitudes etc. du cours de M. Delsarte. Cahier de Van Hymbeck étudiant avec Delsarte (DC, box 8, folder 9, document 2), 1843.

WAILLE, Franck. Corps, arts et spiritualité chez François Delsarte (1811-1871). Des interactions dynamiques. Lille, ANRT, (version de soutenance [2009] en ligne, chapitre par chapitre, à l'adresse https://scd-resnum.univ-lyon3.fr/out/ theses/2009_out_waille_f.pdf), 2011.

WAILLE, Franck. "Les archives de François Delsarte, sources et produit d'un travail scientifique ", in Waille, Damour (2015), p. 19-22, $2015 a$.

WAILLE, Franck. « Retrouver la vitalité des enseignements de Delsarte : expressifs (ni stéréotypés, ni physiognomoniques) et inscrits dans le mouvement (non figés) ", in Waille, Damour (2015), p. 77-94. 2015b.

WAILLE, Franck. " Alfred Giraudet, artiste lyrique et pédagogue delsartien ", in Waille, Damour (2015), p. 113-126, $2015 \mathrm{c}$.

WAILLE, Franck. "Le travail corporel expressif de Delsarte : des observations du quotidien à un entraînement corporel structuré ", in Waille, Damour (2015), p. 273-280, 2015d.

WAILLE, Franck. La méthode somatique expressive de François Delsarte. Historique, esthétique, anthropologique : de la neurophysiologique à la métaphysique. Montpellier: L'Entretemps, 2016.

WAILLE, Franck. "François Delsarte et les arts de la scène : l'enquête américaine ". Mis en ligne sur le site de l'Acfas (Association francophone pour le savoir), juin 2017 (http://www. acfas.ca/publications/decouvrir/2017/06/francois-delsarte-arts-scene-enquete-americaine). 2017.
WAILLE, Franck, DAMOUR, Christophe (dir.) François Delsarte, une recherche sans fin. $\mathrm{Pa}$ ris: L'Harmattan, 2015.

WINKIN, Yves. La Nouvelle Communication. Paris: Seuil, 2000.

(Eu traduzi para o francês os textos vindos do inglês).

Tradução de Clóvis D. Massa.

Recebido: 26/12/2018 Aprovado: 06/07/2018 